\title{
MÁRIO FAUSTINO: A BIOGRAFIA DE UM POETA
}

Lilia Silvestre Chaves*

RESUMO:

o poeta Mário Faustino construiu sua vida como se vivesse em ritmo de (auto)biografia. Recolhendo os rastros que 0 biografado deixou em cartas, fotos, poemas e lembranças de contemporâneos, o texto biográfico - entre ficção e realidade - instaura um diálogo entre teoria, crítica, literatura e histōria.

PALAVRAS-CHAVE: biografia, poesia, vida, amor, morte.

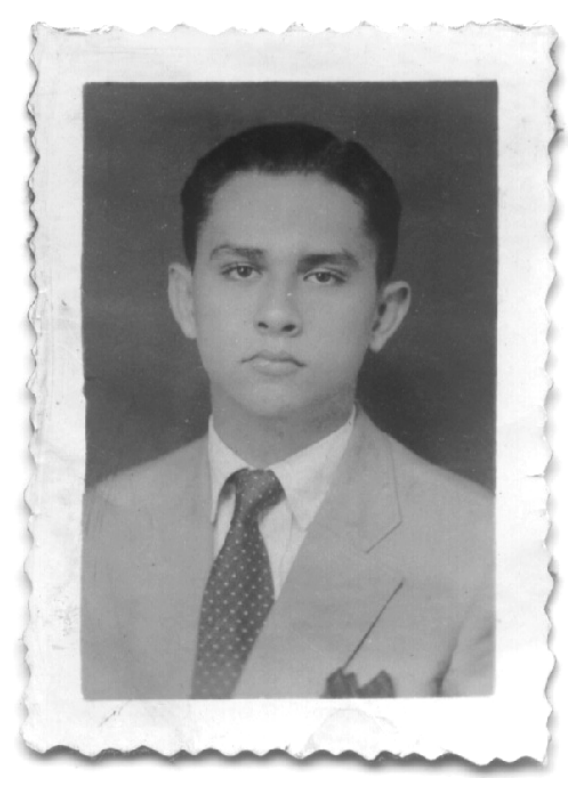

Auto-retrato

Oh não passar somente sugerido! Desespero de nunca ver 0 anjo Não conhecer nem mesmo a rosa e o lírio Ter medo e ter vergonha ajoelhado Querer ser puro e sempre ver-se impuro A espera da morte a incerteza A secreta esperança de ficar A pétala da rosa sob a cota 0 endereço guardado sobre 0 peito Ver navios que chegam e vão sozinhos E depois de tanta dor e tanta angústia Pensar ter dado a luz a algo vivo E levantar-se apenas com o poema.

(18 abr. 1948)

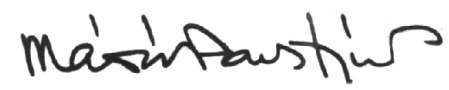

0 texto - Mário Faustino: uma biografia literária - legitima-se pelo nome próprio do título: Mário Faustino. 0 subtítulo é uma espécie de "etiqueta" que define o estudo - "uma biografia literária". Como há um nome próprio real, deduz-se que o texto é verdadeiro. A verdade do nome principal, | Doutora em Letras: Poéticas da Modernidade (Área de concentração: Literatura Comparada), 2004. 


\section{EM TESE}

Belo Horizonte, v. 9, p. I-28I, dez. 2005

a reprodução de lembranças tão nítidas quanto as que a memória das pessoas entrevistadas pôde fornecer, a existência de documentos assinados com o nome do biografado, tudo colabora para que os leitores se certifiquem de que 0 texto não é ficção.

Em qualquer estudo biográfico desfilam muitos nomes. É claro que os leitores mais sensiveis ao uso do nome próprio são os que conhecem as pessoas em foco ou os que conviveram com elas. Refiro-me à questão delicada da biografia como uma espécie de relato revelador de fatos que ainda não haviam aflorado na sociedade em que viveu o biografado. A susceptibilidade quanto a isso costuma ser imensa. Há mais de um tipo de leitores para uma biografia: os que estão envolvidos na vida privada de Mário Faustino, os que conhecem a sociedade que o cercou, os que conviveram com ele nas cidades por que passou ou onde morou, os que o leram e que apenas conhecem a produção literária do poeta ou do crítico, que chegava até eles pelo livro ou pelos jornais, mas que nunca travaram conhecimento com ele. E há, ainda, os que nunca leram nada dele nem a seu respeito, para os quais Mário Faustino bem que poderia ser um personagem de ficção. E em relação ao próprio biografado? É inacreditável que a perspectiva de ter um biógrafo não tenha feito ninguém renunciar a ter uma vida, escreveu, não sem ironia, o filósofo romeno Cioran. Talvez Mário Faustino, por um instante, se tornasse pensativo e grave ao pensar em suas cartas abertas à leitura pública, mas logo voltaria à sonora gargalhada de que todos se lembram, entusiasmado por falarem de sua vida e de sua obra, inseparáveis mesmo depois da morte. E certamente não desistiria de viver como viveu diante da idéia de escreverem a sua história.

Ao voltar-me para uma das tendências atuais da crítica literária - a crítica biográfica - "que possibilita a interpretação da literatura além de seus limites intrínsecos e exclusivo, por meio da construção de pontes metafóricas entre o fato e a ficção (Souza, 2002: 111-120), e desejando trabalhar com poesia, foi em Mário Faustino que pensei. 0 misto de esquecimento e mistério que cercava seu nome animou minha decisão: se Mário Faustino fez o mais ágil e inteligente jornalismo literário do Brasil, se foi um dos nossos maiores críticos literários, lido, semanalmente, por mais de dois anos, em uma página inteira de crítica de poesia em um jornal importante do Rio de Janeiro, 
capital do Brasil, se o lançamento de seu livro 0 Homem e sua hora (uso a grafia usada por Mário Faustino - Homem com maiúscula -, em carta a Benedito Nunes) tornou-se um dos principais acontecimentos da poesia brasileira dos anos 1950, por que havia tão pouca referência à sua vida? Mário morreu muito cedo e sua obra mereceu várias publicações póstumas. Seu nome tem sido lembrado. Nos últimos anos, sua poesia e sua crítica foram novamente editadas pela Companhia das Letras (Boaventura, 2002, 2003, 2004), trazendo alguns textos ainda inéditos. Mas, com exceção de um artigo de Haroldo Maranhão, "0 poeta e sua vida" (Maranhão, 1966), só se encontravam breves dados biográficos do poeta piauiense nos prefácios e apresentações dos livros, em antologias e em histórias da literatura. Decidi preencher essa lacuna e escrever, como tese de doutorado, uma biografia literária de Mário Faustino. 0 Mário do meu Norte, que viveu em Belém do Pará a maior parte da sua vida, um homem do seu tempo, intrigante, rebelde, crítico e poeta, cujo objetivo era "viver ininterruptamente em poesia, em estado poético, escrevendo ou não, mas sempre sob o signo da palavra criadora", um homem cuja criação poética marcou os leitores talvez mais profundamente depois de sua morte do que enquanto viveu. A proposta era fascinante: fazer de uma vida, texto. E situar esse texto biográfico entre teoria e ficção, entre o documento e a literatura, entre a arte e o referente biográfico.

Em Belém, os lugares de memória de Mário Faustino encontram-se reunidos em vários recantos da casa de Maria Sylvia e Benedito Nunes, na antiga Travessa da Estrela, rua que evocava, em Mário, uma lembrança olfativa - "trav. da Estrela: cheiro de lama, capim, sapo, cachorro, livro, tudo mixed up" (Faustino, 1956). Um desses recantos é a biblioteca da torre com a estante repleta de livros que a ele pertenceram. Na biblioteca complementar encontrase 0 arquivo que freqüentei nos anos da pesquisa, na primeira gaveta de um móvel de ferro, aberta para mim por Benedito Nunes. Na poética faustiniana, há duas metáforas que podem se referir à idéia de arquivo: a do solo e a do corpo. 0 arquivo é como um terreno semeado ou como o solo em que se enterram os pedaços do corpo que se transformou em letra e imagem. Repletas de cartas de Mário Faustino, de originais de seus poemas, de projetos inacabados, de recortes de jornais, revistas e fotos, as pastas enfileiradas não jaziam ali inutilmente. Estavam à espera de que alguém profanasse aquele solo. Quando eu o descobri, 


\section{EMTESE}

Belo Horizonte, v. 9, p. I-28I, dez. 2005

a impaciência absoluta do desejo de memória atingiu um de seus fins, predito nos versos de Mário Faustino: - "o resto - silêncio! / sabereis quando nascer / o fruto cujo sêmen planto agora" ("22-10-1956"). Eu não tinha sido a única a tocar aquele corpo, mas, para mim, a história começara naquele momento.

Movimentando-se em uma esfera diferente das que habitualmente envolviam os textos de crítica literária, a crítica biográfica libera-se dos entraves documentários e faz livre uso de qualquer documento. 0 corpus de análise somou aos papéis de Mário Faustino algumas fitas gravadas com entrevistas feitas com amigos e contemporâneos do poeta, abrangendo tanto o texto literário quanto documentos extraliterários, para transformar em palavra uma vida que se queria toda linguagem. A idéia era escrever de maneira que o arquivo se confundisse com o texto, tornando-se parte viva da própria narrativa procedendo a uma espécie de metamorfose do arquivo em história de vida. É este o mistério do arquivo: solo semeado que dá frutos ou túmulo que se pode abrir para despertar o seu conteúdo de um sono profundo, transformando-o no seu contrário - berço ou fonte novamente libertada.

Em minha aventura, enveredei por um caminho crítico novo para mim, voltando-me para uma vida particular e para o que essa vida deixou como legado. Situei-me num lugar intermediário, num discurso entre a biografia propriamente dita e a crítica literária. Se, em uma biografia, normalmente são exigidos os escrúpulos da ciência e os encantos da arte, a verdade sensível do romance e as sábias mentiras da história, como dosar esses vários sentidos acrescidos da reflexão crítica dessa nova biografia que não quer ser mera narrativa? Era indispensável recriar a época ao lado da história pessoal de Mário Faustino e da sua evolução intelectual. No decorrer da narrativa vão aparecendo, como um contraponto, referências ao contexto social, seja pelas epígrafes, por letras de música da época, seja pelas palavras do próprio Mário Faustino sugerindo a história dos lugares onde ele morou, as tendências, movimentos e mudanças que afetaram o mundo durante a vida dele ou mesmo antes dela - pequenos toques do cenário da época esparsos na paisagem mais detalhada da vida do poeta. Foi preciso viabilizar a memória de outros, reconstruir uma ou mais personalidades, analisar e interpretar vida e textos. 0 texto foi se transformando passo a passo, um pouco como a concepção de que a crítica é uma procura que só 
sabe 0 que procura no momento em que o encontra.

Os diversos tons em que se desdobrou a minha escrita têm a ver com os diferentes humores que a inspiraram - meus e dele. A relação entre os momentos que Mário vivia e os episódios relatados fez com que eu sentisse diferentemente a situação que descrevia, e o texto fabricava seu próprio tom, de acordo com a história. Deixei que uma espécie de intuição guiasse a minha dicção segundo os diferentes documentos usados. Encorpei a biografia de Mário Faustino com citações de seus escritos, sem medo de que suas vozes tomassem conta da minha. Misturei a narrativa e o texto crítico à citação de poemas, tentando não cair na armadilha das antigas análises literárias. Citei versos e até poemas inteiros ao lado dos trechos de cartas, artigos, crônicas, exlibris, dedicatórias, rascunhos, fotos, jornais, lembranças de outras pessoas, num vaivém homem-poeta, poeta-homem.

0 texto da biografia, hoje, funde registros diversos: o do testemunho, o da história, o da crítica, o de uma dupla autobiografia. Quem escreve, além de utilizar informações autobiográficas do biografado, ao contar o próprio processo da escrita enquanto percurso e descoberta - numa espécie de meta-narração - acrescenta fragmentos autobiográficos de sua própria história, quebra o enredo para contar algo que aconteceu durante a escrita. No texto-mundo em que viajei, percebi que estive continuamente a criar-me. Eu vivi a ilusão biográfica, e o resultado a que cheguei me convenceu de que a biografia não é uma ilusão. A impossibilidade de escrever uma vida encena ao mesmo tempo a contrafação dessa mesma vida. Percebendo a descontinuidade inevitável de uma vida escrita e seduzida por um tempo não totalmente linear, tracei, em fragmentos, o círculo de sortilégio do meu estudo.

Para Mário Faustino, enquanto poeta, a morte representava o reinício da vida. Sua biografia não poderia deixar de começar por uma espécie de tanatografia: a grafia para a morte e a morte como grafia. Projetando o fim sobre o seu começo, o primeiro capítulo conta a morte violenta de Mário Faustino, aos 32 anos, em um acidente de avião, nos Andes, e a repercussão dessa morte no Brasil. Depois, a partir do seu nascimento, os anos seguem o fluxo natural da cronologia. Há na vida de Mário uma travessia de Norte a Sul, rumo a centros urbanos mais avançados, no mundo intelectual. No segundo capítulo passam-se vinte e cinco anos. Mário nasceu em Teresina, em 1930. Com dez anos mudou-se para Belém. Por meio de pistas e 


\section{EMTESE}

Belo Horizonte, v. 9, p. I-28I, dez. 2005

de indícios - assim como uma arqueóloga monta minuciosamente os cacos pintados de cerâmicas antigas para reconstituir uma cena do teatro grego -, fui colando e interpretando as poucas imagens que existem de Mário criança, para reconstruir sua infância, época em que a única palavra escrita que se tem dele é uma dedicatória.

Apelando para a cumplicidade do leitor, percorri, na galeria de fotos do menino, uma espécie de pré-história de um corpo que se encaminha para o prazer de escrever. A infância termina para nós quando acabam suas fotos. Quando Mário começa a escrever, o seu próprio texto apropria-se do tempo narrativo de sua biografia e nesse sentido, a escrita é a própria afirmação do corpo. Foi em Belém que Mário se tornou poeta e onde viveu até 1955, ano do lançamento de seu livro de poesia O Homem e sua hora (1955). Duas viagens (assunto do terceiro capitulo) fizeram com que se ausentasse da terra e enriqueceram o futuro arquivo com muitas cartas e cartões: de 1951 a 1952, Mário estudou nos Estados Unidos (época em que firmou a sua escolha homossexual) e, em 1953, viajou por inúmeras cidades da Europa.

Durante dois anos, dos quatro que morou no Rio de Janeiro (quarto capítulo), Mário atuou como crítico de poesia, transformando a crítica de rodapé, até então de natureza judicativa, em uma crítica de cunho didático que passou a ocupar uma página inteira do "Suplemento Dominical" do Jornal do Brasil - a página Poesia-Experiência. Em um momento de experiências poéticas, Mário abandonou o projeto de um segundo livro e o poema longo, A reconstrução, para escrever poemas espaciais aparentados com a vanguarda concretista, insistindo, entretanto, na permanência do verso.

As metáforas homoeróticas contidas em seus poemas desde 0 Homem e sua hora tornaram-se cada vez mais audaciosas. E nomes de homens que passaram pela vida de Mário Faustino, ligados a essa época, começaram a aparecer em cartas e depoimentos. Optei por citá-los da maneira como os ouvi ou 1i, sem sobrenome, inclusive aquele que foi sua maior e última ligação, o 0swaldo, simplesmente, ou Leão, como Mário o chamava. É ao lado de Oswaldo que Mário revisita Nova York, em 1960. Nessa ocasião, trabalha na ONU, como tradutor e redator. De lá escreve confessando os verdadeiros pólos Norte-Sul da sua vida: "Minha realidade, Bené, são vocês, e Belém, e um 
certo Rio que conheço. Nova York, para mim, é uma espécie de estação no purgatório [Saison dans le Purgatoire]"(Faustino, 1960a). 0 quinto e último capítulo conta desse amor, desse trabalho e do homoerotismo na poesia de Mário Faustino, que voltou ao Rio no final de 1960. Ainda reviu Belém, mais uma vez, e, em novembro de 1962, tomou o avião que o levou à morte.

Dois anos antes de morrer, Mário Faustino selou a união entre sua vida e sua poesia ao pronunciar as palavras rituais "até que a morte nos separe", firmando um pacto que cumpriu religiosamente. Para ele a experiência poética sempre foi indissociável de sua vivência, embora, como categoria existencial pura, o vivido oponha-se ao escrito, que ele alimenta. Se a vida pode coincidir com a obra, Mário Faustino é o poeta por excelência para ilustrar essa questão, com o seu ideal de viver a vida em tempo de poesia, fazendo coincidir o tempo verbal com o tempo vivido. Seu poema longo, inacabado e eterno, coincidiu com a vida curta que se fragmentou pelo caminho, efêmera e inacabada.

Uma das imagens mais freqüentes da mítica contemporânea é a do artista morto no auge de sua carreira e criatividade. A morte assume o emblema da perfeição, do pacto sereno, da experiência-limite. Esse culto ao gênio trágico, ao mártir precoce, valorizando os aspectos da personalidade, não foi a intenção da tese que não quis destacar nenhuma particularidade da vida de Mário Faustino, nem focalizar somente a sua poesia. Talvez vise apenas diminuir a distância entre o homem, o poeta e seus leitores.

A vida de Mário Faustino faz integralmente parte de sua obra. Não a explica, identifica-se com ela, permanece uma de suas criações, e não a menos interessante. Mário, fazedor que era, inventou-a, tanto quanto pôde, diferente da vida comum, vigiou-a, favoreceu algumas vezes as suas metamorfoses, pisou em atalhos incomuns. Fabricou também a sua morte, amou-a, riu dela, previu-a. No século da máquina, Mário Faustino esforçou-se por se tornar um outro Orfeu, transgressor, que garantisse a imortalidade, guiando a si próprio e ao seu tempo vivido no caminho pelo Hades até o seu retorno ao mundo, transfigurado em palavra. No solo místico de sua poesia, a reinvenção de Mário persegue um Orfeu brasileiro e também reinventado: o de Jorge de Lima. E é 


\section{EMTESE}

Belo Horizonte, v. 9, p. I-28I, dez. 2005

recortando um verso de Jorge de Lima que insisto: Mário se escrevia aquém e além da palavra.

Nas suas lições de poética, Paul Valéry falava do momento difícil do arremate de um texto, em que o escritor, por mais que tenha retomado, retocado, refeito sua obra, considera-a muito distanciada do sonho que tivera em relação a ela e, no entanto, ele a abandona, contrariado, porque sente que não poderia fazer melhor. Quando a escrita toma direções inesperadas, o sentimento é exatamente este: partimos de um desejo, de uma idéia e em algum momento o rumo se dispersa. Se um trecho de carta situava para mim o percurso de Mário, uma dedicatória me revelava um segredo, ou um verso iluminava um capítulo apenas esboçado, de repente a vida que corria paralela ao estudo me fazia estacar. E assim eu fui, o tempo inteiro, "em concentrado prazo de irresolução" (como diria Guimarães Rosa). Há sempre uma vontade de recomeçar, de voltar no tempo para rever as diferentes espécies de rasuras pelas quais passou o percurso dessa biografia. Mas chegou, enfim, o momento da aventura biográfica se completar (aventura nos vários sentidos de acontecer, de relacionamento amoroso e de ventura).

0 nome de Mário Faustino não se apagou. Último suspiro que fica das coisas quando a vigília adormece, o nome é um presságio, é o princípio, o fim e o reinício. Talvez eu possa mais uma vez usar as palavras de Mário Faustino para descrever também um sentimento meu: "No fundo, sei que, afinal de contas, com todos os erros e tropeços, tudo está absolutamente certo e o fim há de justificar o curso. 0 fim: o começo de uma outra coisa que nunca saberemos, ou a volta ao princípio, ou... Tudo isso me dá uma embriaguez maravilhosa mas no fundo da qual persiste um certo terror...". (Faustino, 1960b)

0 choque do avião contra as montanhas, que provocou a morte do poeta, é apenas uma imagem da qual se imagina o ruído, como se estivéssemos diante de um quadro. Na obra de Mário Faustino, inúmeros versos repetem a fixação na morte prematura, no tempo breve, na própria metamorfose, delicada e atroz imagem de movimento. Depois de sua morte, seu corpo transformou-se em letra. 0 conjunto da obra poética e da vida nos revela afinal as múltiplas relações que existem entre a morte, 0 sexo, o corpo, o movimento, a partida e a paz. 
A sua poesia continua sempre fluindo, indo, partindo. Quando comecei a escrever sua vida, há três anos, eu também estava de partida. Tal como ele, "passageiro alumbrado" dos livros, eu viajava dentro das páginas e para além, vivendo o livro como um mundo e o mundo como um livro. A vida escreveu-se ao ritmo do caminhar de quem trabalha sem o plano rigoroso de selar a verdade. Como o biografado, também empreendi o exílio nas palavras, vivi a contradição entre a biblioteca e a viagem e a angústia de ter que dividir a realidade com a vida irreal, desejando, como ele, que a linguagem esquecida renascesse pela memória, na tênue sobrevivência da própria linguagem literária, que permite à memória falar.

Eu segui até aqui. Ele permanece entre a energia da partida, a certeza de renascer, da pureza original, da esperança de se tornar geográfico e eterno na sua poesia da não-chegada, à espera de novas mãos que o arrebatem em seu alado pé de verso. A morte esperava-o na fronteira entre o Brasil e um país estrangeiro, em um deserto de neve. A cordilheira é um não-lugar, seu relevo, irregular, suas cores, sem nome. Sobrevoando a imensidão dos Andes, perde-se completamente o norte, a hora e o lugar, as noções terrestres não têm mais sentido durante a viagem. Sem tempo, nem espaço, o que existe é uma fenda entre o passado e o futuro imediato: "A vitória pertence ao tempo que no ar / Agita um homem só, troféu tripudiado / Pela noite..." ("Soneto marginal"). Uma explosão na noite sobre o branco das neves nas montanhas dos Andes transfigura o contorno do horizonte, confunde o esplendor das estrelas, atinge distâncias, espalhando as chamas no negrume do céu sem luzes e os destroços de sangue e ferro. Os Andes peruanos foram palco de alguns acidentes aéreos, palco sobre o qual desceu o silêncio branco das neves e do olvido, até que outro tempo descobrisse o poeta e sua história. Meu trabalho acabou diante daqueles fogos, na neve. Na vida toda linguagem, as "chuvas de sêmen sobre campos de sal" semearam versos e verbos, e transformaram o rumo de alguns textos, o meu entre eles. 


\section{EM TESE}

Belo Horizonte, v. 9, p. I-28I, dez. 2005

ABSTRACT :

The poet Mario Faustino constructed his life as if he lived in an autobiographical rhythm. Retracing the footsteps left by the poet, collecting letters, photos, poems and memories of contemporary friends, the biographic text between fiction and reality - initiates a dialog between theory, criticism, literature and history.

KEY WORDS: biography, poetry, life, love, death.

REFERÊNCIAS BIBLIOGRÁFICAS

BOAVEnTURA, Maria Eugenia (Org.). Mário Faustino: Homem e sua hora e outros poemas. São Paulo: Companhia das Letras, 2002.

BOAVENTURA, Maria Eugenia (Org.). De Anchieta aos concretos. São Paulo: Companhia das Letras, 2003.

BOAVENTURA, Maria Eugenia (Org.). Artesanatos de poesia. São Paulo: Companhia das Letras, 2004.

FAUSTINo, Mário. Carta a Benedito Nunes, Rio, 4 set. 1956 (Arquivo de Benedito Nunes, em Belém).

FAUSTINo, Mário. Carta a Benedito Nunes. Nova York, 2 ago. 1960a.

FAUSTINo, Mário. Carta a Walmir Ayala. Nova York, 2 ago. 1960b.

MARANHÃO, Haroldo. 0 poeta e sua vida. O Estado de $S$. Paulo, São Paulo, 9 jul. 1966. Suplemento Literário.

SOUZA, Eneida Maria de. Notas sobre a crítica biográfica. In:__ Crítica cult. Belo Horizonte: Faculdade de Letras da UFMG, 2002. 